\title{
Closing Coal: Economic and Moral Incentives
}

\author{
Paul Collier and Anthony J. Venables
}

May 2014

Centre for Climate Change Economics and Policy Working Paper No. 176

Grantham Research Institute on Climate Change and the Environment

Working Paper No. 157 
The Centre for Climate Change Economics and Policy (CCCEP) was established by the University of Leeds and the London School of Economics and Political Science in 2008 to advance public and private action on climate change through innovative, rigorous research. The Centre is funded by the UK Economic and Social Research Council and has five inter-linked research programmes:

1. Developing climate science and economics

2. Climate change governance for a new global deal

3. Adaptation to climate change and human development

4. Governments, markets and climate change mitigation

5. The Munich Re Programme - Evaluating the economics of climate risks and opportunities in the insurance sector

More information about the Centre for Climate Change Economics and Policy can be found at: http://www.cccep.ac.uk.

The Grantham Research Institute on Climate Change and the Environment was established by the London School of Economics and Political Science in 2008 to bring together international expertise on economics, finance, geography, the environment, international development and political economy to create a worldleading centre for policy-relevant research and training in climate change and the environment. The Institute is funded by the Grantham Foundation for the Protection of the Environment and the Global Green Growth Institute, and has five research programmes:

1. Global response strategies

2. Green growth

3. Practical aspects of climate policy

4. Adaptation and development

5. Resource security

More information about the Grantham Research Institute on Climate Change and the Environment can be found at: http://www.lse.ac.uk/grantham.

This working paper is intended to stimulate discussion within the research community and among users of research, and its content may have been submitted for publication in academic journals. It has been reviewed by at least one internal referee before publication. The views expressed in this paper represent those of the author(s) and do not necessarily represent those of the host institutions or funders. 


\title{
Closing Coal: \\ Economic and Moral Incentives*
}

Paul Collier

Anthony J. Venables

This study was originally commissioned for the Grantham Research Institute "Green Growth and a new Industrial Revolution" research programme, generously funded by the Global Green Growth Institute. A version will be published in the Oxford Review of Economic Policy later this year.

\begin{abstract}
:
Climate policy requires that much of the world's reserves of fossil fuels remain unburned. This paper makes the case for implementing this directly through policy to close the global coal industry. Coal is singled out because of its high emissions intensity, low rents per unit value, local environmental costs and sheer scale. Direct supply policy - the sequenced closure of coal mines - may lead to less policy leakage (across countries and time) than other policies based on demand or price management. It also has the advantage of involving relatively few players and leading to clear-cut and observable outcomes. Appropriately sequenced closure of the world coal industry could, we suggest, create the moral force needed to mobilize collective international action.
\end{abstract}

Keywords: climate change, coal, cap and trade, supply policy.

JEL classification: Q3, Q4, Q54

Authors' Addresses:

Paul Collier

Blavatnik School of Government

Merton St

Oxford

OX1 4JE

UK

Paul.collier@bsg.ox.ac.uk
A.J. Venables

Department of Economics

Manor Road

Oxford

OX1 3UQ

UK

tony.venables@economics.ox.ac.uk

* Thanks to Cameron Hepburn, Larry Karp, Rick van der Ploeg, a referee and participants in conferences at the Grantham Institute and Oxford for valuable comments, and to Keith Miao for research assistance. 


\section{Introduction}

Global warming is an extreme instance of a collective action problem. To prevent the stock of carbon in the atmosphere from crossing a dangerous threshold we all need to change our behaviour and reduce our emissions: the adverse externalities of our actions need, through some mechanism or other, to become internalized. Some of these changes will be large - the development of new technologies and closure of old ones - and others small, the myriad of changes in the day to day behaviour of households and firms. The advantage of carbon taxes or of pricing and trading emissions is that it induces households and firms to make these changes, potentially in an efficient manner. However, despite being pursued for the past decade, the approach has had limited traction: global emissions are currently projected to continue to increase until at least 2030.

Even if it were efficient in economic terms, the present approach is very inefficient as a strategy for mobilizing global action. The diffuse nature of the actions required means that there is very little moral pressure on decision takers to act. Actions are not readily observable and outcomes are highly uncertain, meaning that there is little apparent link between actions and their effects, and hence no way to attribute either blame or credit. As a consequence countries find it easy to free-ride rather than to join a coalition of others pursuing active climate policy. A small coalition controls only part of world emissions, and its effectiveness is further undermined by the problem of leakage: countries outside may act in ways that offset or undermine mitigation policies.

These observations motivate the proposal of this paper in which we argue the case for policy to act directly on large and observable aggregates: in particular, policy to progressively close the world coal industry. At present 43 percent of $\mathrm{CO} 2$ emissions from fuel combustion and nearly 25 percent of total CO2e emissions come from coal. Further, both the level and share of coal in emissions has been increasing (see figure 1). As we elaborate in Section 2, since coal is the key polluting fuel, any successful strategy for combating global warming will have the closure of coal as a major consequence.

Focusing on actions to directly reduce the supply of fossil fuel has two important advantages. One is that it provides new opportunities for implementation, through both market incentives and enhanced moral pressure to participate in collective action. The other is that targeted supply side policy reduces some of the leakage problems. Of course, the myriad of small changes in behaviour must still be made; existing policy instruments remain important, and these will be reinforced by the price changes that will follow from closing coal. 


\section{Figure 1}

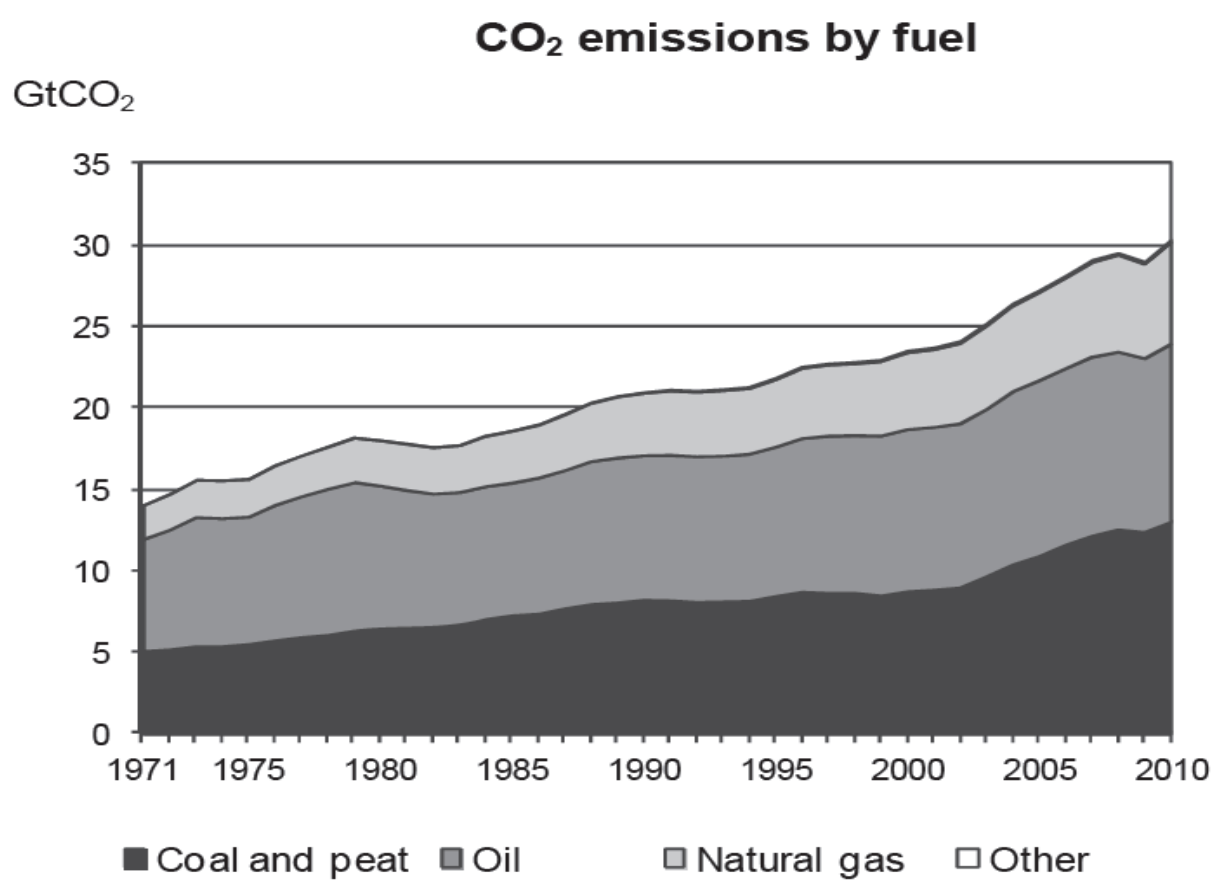

Source: CO2 emissions from fuel combustion; highlights: IEA 2012

Following our outline of the case for closing coal in Section 2, remaining sections look at policy instruments. Our focus on the supply of fossil fuels contrasts with the prevailing emphasis of carbon taxation and cap-and-trade on demand. In each case, if only some decision takers adopt the policies, a 'coalition of the willing,' their effectiveness is diminished by leakage, and this is the subject of Section 3. Leakage takes two broad types. One is international: not all countries implement these policies, and action to reduce carbon emissions in one group of countries may, via general equilibrium reallocations, increase emissions in other countries. The other is inter-temporal: expectations of future policy action may cause the burning of fossil fuels to be brought forward, having the perverse effect referred to as the 'green paradox'. Although both demand-based and supply-based policies suffer from leakage, we show that there are reasons to expect leakage problems to be less severe with targeted supply side policies, particularly in the context of coal.

In Sections 4-6 we turn to implementation. The closure of the global coal industry requires a series of decisions by politicians and coal mining companies which are not currently in their interest. These decisions will only happen if economic incentives, moral pressure, or both, are brought to bear on them. In Section 4 we consider economic incentives. Focusing on a single industry has a number of practical advantages in incentive design. The number of actors whose behaviour is to be targeted by the incentives is drastically reduced from a vast and diffuse group of consumers and producers to a small and precise group of coal mining companies. Further, the pertinent decisions of these actors are much easier to observe: mines must close. Finally, the consequences of these decisions are known with certainty in contrast to the imprecision of the demand-based approaches. Beyond these practical 
advantages, as Harstad (2012) has recently shown, payments by the coalition of the willing to secure closure of the global coal industry can achieve an outcome that is, from the standpoint of the coalition, efficient. We consider a modification of the Harstad proposal in which instead of a coalition of atypically moral countries, coal producers are compensated by a ring-fenced cap-and-trade scheme in which the rents from oil are used to buy-out the much lower rents from coal.

All action on global warming relies to some degree upon moral pressure. While the collective action problem can be reduced if governments adopt well-designed incentives, moral pressure is essential for governments to adopt these incentives. In Section 5 we develop a theory of moral pressure and apply it to the process of closing coal. Whereas Harstad treats the coalition of the willing as exogenous - some countries care about climate change, others do not - ultimately participation is endogenous to the degree of moral pressure brought to bear on each country. While economists concerned with climate change have recognized the need for moral pressure, to date the strategy for achieving it has been the simple one of exhortation in which the dangers of inaction are emphasised. Yet recent advances in social psychology are revealing moral pressure to be as complex and sensitive to design choices as the incentives with which economists are more familiar.

We draw on this work to suggest how it might be more feasible to generate decisive moral pressure for the gradual closure of coal than it is for other approaches to climate policy. The essential insight is that moral pressure depends upon establishing a sequence of moral responsibility for closure decisions. At any one time only a very few actors should bear the entire moral responsibility for action, but their compliance would trigger a reassignment of responsibility. To be accepted, the sequence must be perceived as fair, and this in turn must be derived from a moral context. This suggests a scheme in which coal producers agree to sequence closure, with high income countries going first. This could be combined with a ring-fenced cap and trade scheme for fossil fuel extraction. While economic incentives can undermine moral incentives, in this case trade in extraction permits would amount to payments from oil rents to countries closing coal (and potentially compensating the lost earnings of mineworkers), carrying the moral force of fairness.

\section{The case for closing coal}

If the probability of warming by $2^{\circ}$ or more is to be kept below 50 percent, some 60 80 percent of booked fossil fuel reserves are 'unburnable' (Grantham Institute 2013). The implication of this astonishing statistic that has to date received most attention is the problem of 'stranded assets': the current valuations of energy companies assume that all these unburnable reserves are fully exploitable. We focus on another implication: if most fossil fuels reserves will have to remain unexploited, there are potentially large gains from a mechanism which selects for extraction only those reserves which maximize the net social benefit per unit of $\mathrm{CO} 2$ emitted. We suggest in this section that coal is the predominant fuel that should be unburnt. As noted in the Introduction, the closure of coal is essential if only due to its sheer scale. Not only does coal dominate flow usage (Fig. 1), but it also dominates proven reserves. The estimated reserve to annual production ratio for coal is 110 , as compared to 50 for oil (BP 2013). However, coal is not just dominant; it is distinctive, both in terms of emissions and rents. 
Coal has markedly higher emissions of $\mathrm{CO} 2$ and other pollutants per unit of energy than other fossil fuels. They are nearly twice those of natural gas (in the range $75-95$ percent higher depending on the type of coal) and are 30-40 percent greater than for oil. ${ }^{1}$ We note that the prospect of carbon capture and storage (CCS), despite years of investment, remains far away from large scale operation. To quote from the Grantham Institute's 'Unburnable Carbon 2013' study, 'the relatively limited deployment of CCS that is expected before 2050, even in an idealised scenario, means that it is unlikely to significantly increase the amount of fossil fuels that can be burned'. 2

While generating higher emissions, coal also generates lower economic rents, and hence smaller losses to owners from leaving coal in the ground. ${ }^{3}$ Estimates of this rent are hard to come by, but there are a number of indicators. The share of extraction costs in price suggests that costs are significantly higher for coal than for other fossil fuels, in particular oil. This is specific to particular mines or fields and some estimates are given in table 1. Using years in which (coincidentally) the price per tonne of coal is similar to the price of a barrel of oil (at \$106 each), the table illustrates that earning this price incurs extraction costs on average 60 percent more for coal than for oil. Only when the least-cost coal (that from China, India and a few other developing country producers) is matched against the highest-cost oil (that not from the Middle East) are costs comparable. ${ }^{4}$ Additionally, coal has high transport costs (cif, carriage, insurance and freight) which may reduce the price received by producers (fob, free on board) by several tens of dollars per tonne. Even for shipments within the US, transport costs account for an average of $35 \%$ of the delivered price of coal (Bowen and Irwin 2007) and for the $15 \%$ of coal that is internationally traded costs are higher.

Corresponding to higher extraction and transport costs, coal has much lower rent per dollar of output. A nice summary way of thinking about the economic surplus that would be lost by closing coal is given by Grantham (2013). For the top 200 fossil fuel companies, coal accounts for around 36-42 percent of their booked $\mathrm{CO} 2$ reserves (p14) but just 16 percent of market value. This suggests that the present value of the

\footnotetext{
${ }^{1}$ See, for example, European Environment Agency (2008) for data on emissions from EU power plants by fuel source.

${ }^{2}$ Grantham Institute (2013), p 13.

3 Rents include those accruing to owners and to tax authorities. Globally, coal receives public subsidies, although these are relatively small at around $\$ 6.5 \mathrm{bn}$ per year out of total subsidies to fossil fuels of \$500bn a year, see Clements et al (2013)

4 This comparison benchmarks against the value of output (i.e. cost of producing $\$ 106$ worth of output) which is the pertinent economic metric. A tonne of coal produces four to five times as much energy as a barrel of oil, so extraction costs per unit energy are significantly lower for coal than for oil, but this is offset by higher costs of transport and less valuable by-products. 1 barrel oil = $6.1 \mathrm{GJ} ; 1$ tonne coal, 27-30 GJ: 1 cubic metre of natural gas 38.3 MJ.

https://bioenergy.ornl.gov/papers/misc/energy_conv.html
} 
rent loss associated with coal is relatively small, estimated (for these companies) at approximately $\$ 640$ bn (Grantham 2013 p27).

Table 1: Production, costs and rent for coal and oil

\begin{tabular}{|c|c|c|c|c|c|c|c|}
\hline \multirow{2}{*}{$\begin{array}{c}\text { Steam Coal: } \\
\text { Countries }\end{array}$} & \multicolumn{3}{|c|}{2010 , price $\$ 106.7$ per tonne cif } & \multicolumn{4}{|c|}{ Oil: 2011 , price $\$ 106$ per barrel } \\
\hline & $\begin{array}{l}\text { Production } \\
\text { tonnes pa } \\
\text { (million) }\end{array}$ & $\begin{array}{l}\text { Extraction } \\
\text { cost } \\
\$ / \text { tonne }\end{array}$ & $\begin{array}{l}\text { Rent + cif } \\
\text { \$/tonne }\end{array}$ & Countries & $\begin{array}{c}\text { Production } \\
\text { barrel pa } \\
\text { (million) }\end{array}$ & $\begin{array}{c}\text { Extraction } \\
\text { cost } \\
\$ / \text { barrel }\end{array}$ & $\begin{array}{c}\text { Rent } \\
\text { \$/barrel }\end{array}$ \\
\hline China & 3235.0 & 37.8 & 69.0 & Saudi Arabia & 4067 & 10.0 & 96.53 \\
\hline USA & 983.7 & 74.0 & 32.7 & Russia & 3836 & 28.0 & 78.53 \\
\hline India & 573.8 & 22.1 & 84.6 & USA & 2872 & 35.8 & 70.72 \\
\hline Australia & 424.0 & 63.0 & 43.7 & Iran & 1591 & 13.0 & 93.53 \\
\hline Russia & 321.6 & 78.0 & 28.7 & China & 1487 & 23.3 & 83.19 \\
\hline Indonesia & 275.2 & 48.0 & 58.7 & Canada & 1287 & 33.5 & 73.00 \\
\hline $\begin{array}{l}\text { South } \\
\text { Africa }\end{array}$ & 257.2 & 52.0 & 54.7 & UAE & 1211 & 10.0 & 96.53 \\
\hline Germany & 182.3 & 46.0 & 60.0 & Kuwait & 1051 & 10.0 & 96.53 \\
\hline Poland & 133.2 & 40.0 & 66.7 & Iraq & 1022 & 9.0 & 97.53 \\
\hline Colombia & 74.4 & 42.0 & 64.7 & Venezuela & 1010 & 37.0 & 69.53 \\
\hline Canada & 68.0 & 53.0 & 53.7 & Nigeria & 898 & 28.0 & 78.53 \\
\hline Czech Rep. & 55.2 & 53.3 & 53.4 & Brazil & 800 & 21.8 & 84.75 \\
\hline Mexico & 12.0 & 32.7 & 74.0 & Qatar & 670 & 7.0 & 99.53 \\
\hline Venezuela & 2.7 & 56.0 & 50.7 & Kazakhstan & 642 & 14.9 & 91.60 \\
\hline
\end{tabular}

Source: BP Statistical Review: Wealth of Nations data set, WB: IEA World Energy Outlook.

A further cost of coal arises from the localized pollution caused by burning coal. New research is highlighting the extreme levels of damage that these emissions cause. For example, Chen et al. (2013) find that exposure to high levels of particulates from coal burning in Northern China reduced life-expectancy by an astonishing five years. The health costs attributable to coal burning in Europe are estimated to run at between $€ 15$ and $€ 40$ bn per annum (Health and Environment Alliance 2013). While local populations in the vicinity of where coal is burnt would secure large gains from the closure of coal, populations in the vicinity of where coal is extracted would suffer large losses. Coal mining is distinctive in requiring a large, specialized workforce, which is spatially highly-concentrated and often remote from large centres of employment. These features imply both that coal miners would suffer substantial economic and social costs from closure, and that they would find organized political opposition to closure relatively easy. Hence, while closing coal is economically attractive, it is politically difficult and this obstacle has to be addressed by some combination of financial incentives and moral pressure.

\section{How supply side measures can address the problem of leakage}


Climate policy can be implemented through a variety of measures. Carbon taxes or cap-and-trade raise the price of carbon to those who burn fossil fuels; they can be complemented by measures to promote development of alternative sources of energy or to manage demand directly (e.g. through efficiency regulations). Supply measures operate directly on extraction of fossil fuels, closing down sources of supply. If policies are implemented by all countries (or more broadly, all decision takers), these measures can achieve equivalent quantity effects; reducing demand will lead to a reduction in quantity supplied, and vice versa. However, the equivalence breaks down if policies are implemented by some, but not all, decision takers. This is the problem of leakage, and it arises in two contexts. One is international: not all countries implement these policies, and policy to reduce carbon emissions in one group of countries may, via general equilibrium reallocations, increase emissions in other countries. The other is inter-temporal: expectations of future policy action may cause burning of fossil fuels to be brought forward, having the perverse effect sometimes referred to as the green paradox (Sinn 2008, 2012).

\section{International leakage:}

On any conceivable practical scenario for the implementation of either carbon taxes or cap-and-trade, the policy is initially implemented by a coalition-of-the-willing (henceforth 'the coalition') with many other countries choosing not to participate. International leakage concerns the responses of those outside the coalition. Carbon taxes and cap-and-trade have the effect of reducing demand for fossil fuels in the coalition, and thereby reducing the producer (supply) price of the fuel. Policies which directly reduce demand (e.g. efficiency regulations) have the same effect. In the case of carbon taxes or cap-and-trade the price to consumers will increase, while the price received by producers will be lower. In both cases, the price that holds in countries outside the coalition is reduced and this creates an incentive for consumption of the fuel to increase in these countries, and for production to fall. The net effect on carbon leakage and hence total emissions depends on the magnitude of these quantity responses, as determined by price elasticities of demand and supply. Broadly speaking, leakage from demand policies will be larger the more price elastic is demand relative to supply. ${ }^{5}$

Conversely, policies which operate to reduce supply will increase prices outside the coalition; the price increase reduces non-coalition demand but may increase supply. Leakage from supply policies will consequently be larger the more price elastic is supply relative to demand. The literature therefore suggests that leakage will be reduced by using policies targeted at supply (rather than demand) if price elasticities of demand are high relative to elasticities of supply (Harstad 2012). ${ }^{6}$

\footnotetext{
${ }^{5}$ For careful analyses of these issues see Hoel (1994), (1996) and Harstad (2012).

6 An additional instrument that could be used to address leakage is a border tax adjustment, see Jakob et al. (2013).
} 
How do these arguments play out in the context of coal? The key point is the existence of demand side substitutes for coal, in the form of oil, gas and renewables; the long run price elasticity of demand for a single fuel source (coal) is therefore likely to be high, even if the elasticity of demand for energy as a whole is low. These substitution possibilities in demand have no analogue on the supply side; producing less coal has no technological link to having a greater supply of oil, gas or renewables. This suggests that long run price elasticities of demand are likely to be high relative to supply elasticities, implying that supply side policies will result in less carbon leakage.

There are sufficiently many moving parts in this argument that some formalisation and an example are helpful. A model of supply and demand for two fuels ( $\mathrm{C}$ and $\mathrm{G}$, which we think of as coal and either gas or 'green' renewables) is presented in the appendix. In the text we describe its operation using a numerical example. We suppose that demand for energy as a whole is quite price inelastic (set at unity), but there is a high degree of substitutability between alternative fuel sources $C$ and $G$ (elasticity of substitution set at 5). Supply elasticities are set at unity for both fuels ${ }^{7}$, and the initial benchmark equilibrium has the two fuels used in equal amounts.

We look just at policy towards coal (C), focusing on the question of whether leakage is greater or less with demand or supply policies. The demand policy is a 50 percent downwards shift of the demand curve of half the consumers of $\mathrm{C}$ (i.e. the coalition is assumed to be half the world). The supply policy is a 50 percent downwards shift in the supply curve of half the producers of C. Crucially, half of the consumers and half of the producers do not implement policy, although they are affected by the ensuing price changes and equilibrium reallocation. The two policies are scaled to be the same size but their effects on equilibrium prices, quantities and emissions are quite different and are given in the first two rows of table 2.

${ }^{7}$ Inter-temporal issues are developed in the next section 
Table 2: International leakage: demand vs supply policies.

\begin{tabular}{|l|ccccccc|}
\hline \multicolumn{1}{|c|}{ Policy: } & $\mathrm{P}_{\mathrm{C}}$ & $\mathrm{P}_{\mathrm{G}}$ & $\mathrm{P}_{\mathrm{C}} / \mathrm{P}_{\mathrm{G}}$ & $\mathrm{X}_{\mathrm{C}}$ & $\mathrm{X}_{\mathrm{G}}$ & Emission* & Emission** \\
Supply reduction & 1.10 & 1.05 & 1.05 & 0.82 & 1.05 & 0.89 & 0.82 \\
Demand reduction & 0.91 & 0.95 & 0.95 & 0.91 & 0.95 & 0.92 & 0.91 \\
Carbon tax * & 0.91 & 0.97 & 0.94 & 0.91 & 0.97 & 0.93 & \\
Carbon tax ** & 0.91 & 1.04 & 0.87 & 0.91 & 1.04 & & 0.91 \\
\hline
\end{tabular}

All variables relative to value with no policy.

* G emissions per unit $1 / 2$ of C; Row 3, Tax rates $t_{C}=40 \%, t_{G}=20 \%$ initial price.

** G has 0 emissions: $\quad$ Row 4: Tax rates $t_{C}=40 \%, t_{G}=0$.

The first two columns give price effects and, as expected, the supply policy raises prices while the demand policy reduces them. (All variables are expressed proportional to their value in the absence of policy). Since the policy is on $\mathrm{C}$, the primary impact is on the world price of $\mathrm{C}, \mathrm{P}_{\mathrm{C}}$, although $\mathrm{P}_{\mathrm{G}}$ moves in the same direction, albeit by a much smaller amount. (Thus, in row 2 , the lower $\mathrm{P}_{\mathrm{C}}$ causes some substitution from $\mathrm{G}$ to $\mathrm{C}$ which brings down $\mathrm{P}_{\mathrm{G}}$ ). Importantly, the relative price, $\mathrm{P}_{\mathrm{C}} / \mathrm{P}_{\mathrm{G}}$ (column 3) moves in opposite directions under the two policies. The next two columns give the quantity changes. The supply policy brings about a much larger reduction in $\mathrm{C}$ use (down18\% rather than 9\%), with a small increase in consumption of $\mathrm{G}$. The final two columns give the impact on emissions, the first column doing the calculation when $\mathrm{G}$ has half the emissions of $\mathrm{C}$, and the final with $\mathrm{G}$ being completely clean. The greater effectiveness of the supply policy is apparent: the reduction in emissions is doubled.

The final two rows of the table look at emissions taxes imposed by the coalition but not in other countries. These taxes are proportional to emissions, so that $\mathrm{G}$ is taxed less heavily than $C$, and this causes consumers in coalition countries to substitute $G$ for $\mathrm{C}$. Within the coalition this is as intended, and reduces emissions. However, the demand substitution means that $\mathrm{P}_{\mathrm{C}} / \mathrm{P}_{\mathrm{G}}$ falls so (as with demand reduction) $\mathrm{C}$ becomes relatively cheaper outside the coalition. The net effect on emissions reduction is correspondingly small, as indicated in the final two columns.

This model and example serves to illustrate the more general arguments about leakage under demand and supply policies and to demonstrate the importance of substitution between fuels. While just an example, the important message concerns the relative price changes and consequent impact on fuel choice. Many countries are on the point of installing very large amounts of electricity generating capacity. These choices need to be made on the basis of an increase in the price of coal relative to other fuels, not a decrease. This price signal is brought about by policy-active countries pursuing 
supply side policy. Demand policy and a carbon tax both have the perverse effect of encouraging the wrong choice of technology in countries outside the coalition.

\section{Inter-temporal leakage:}

Inter-temporal leakage arises when, for a finite fossil fuel, the expectation of future policy brings a change in the rate at which the fuel is extracted and burnt. The green paradox occurs if expectation of stronger policy in future causes current and nearfuture emissions to increase in anticipation of this change. Is this likely to be more or less of a problem for coal than for other fuels, and if so can supply measures mitigate the problem?

The salient features of coal as compared to other fossil fuels (in particular oil) are high extraction costs and large stocks. As a consequence scarcity rents are low, as we saw in table 2. If scarcity rents are entirely absent then the green paradox is inapplicable. The resource is essentially unlimited and extraction ceases to be an inter-temporal problem; expectation of future policy therefore has no bearing on current extraction. However, if there is some rent element, even small, inter-temporal substitution may occur. ${ }^{8}$ Furthermore, this will tend to be greater the larger are the stocks of the resource simply because a large stock of the resource means that proportionately small changes in the time profile of extraction have a large effect on the quantities extracted at various dates. There are two aspects to this size effect. One is simply the large stock. The other is that because of high extraction costs and low rents the rate of price increase (along a Hotelling path) is small. Given demand curves, this means that the extraction profile of coal, compared to oil, is relatively skewed towards the future; and since future extraction is large relative to present, a policy change that brings forward extraction will have a large current impact.

This outcome is easily demonstrated in the simplest possible model that captures the salient features of coal versus oil (although its robustness to a wider range of situations remains to be tested). Suppose that extraction costs $(\mathrm{K})$ are constant per unit output and independent of remaining stock. There is a fixed stock of the resource (S) and as a consequence there is scarcity rent. The price of the resource will therefore be equal to $\mathrm{K}$ plus a rent per unit. We compare two resources. One (coal) has high $\mathrm{K}$ and high S; the other (oil) has low $\mathrm{K}$ and low S. Comparison is most easily made in a numerical example (formal model in the appendix) which works with three time periods and is reported in table 3. The first two rows represent 'oil' and the second two 'coal', the latter having twice the initial reserves and (slightly more than') twice the extraction costs. Optimal depletion of these stocks (given constant demand) is computed for each industry, first with no policy (rows 1 and 3, tax in each period

\footnotetext{
${ }^{8}$ Lemoine (2013) uses an event study (the unexpected collapse of the US Senate's climate bill in 2010) to demonstrate that green paradox effects are present in coal.

${ }^{9}$ Exact value chosen such that first period output $\mathrm{X}_{1}$ is the same in both industries. There is no demand for either fuel beyond period 3 .
} 
equal to zero) and then with an expected tax imposed in the second and third periods $\left(t_{2}=t_{3}>0\right.$, rows 2 and 4$)$. In the initial situation without policy (rows 1 and 3$)$, the share of rent in price (in the first period) is more than half in oil $(0.51 /(0.4+0.51)$ but just 7 percent in coal $(0.06 /(0.85+0.06)$. As a consequence the Hotelling price path is much steeper for oil than for coal. Given the same demand functions for the two fuels, production in each of the three periods $\left(\mathrm{X}_{1}, \mathrm{X}_{2}, \mathrm{X}_{3}\right)$ is much more skewed to the present for oil than it is for coal.

For present purposes, the question is: how does future expected policy affect current extraction? Imposing the expected future tax, $\left(t_{2}=t_{3}>0\right.$, rows 2 and 4$)$, we see that the green paradox operates in both industries with period one production, $\mathrm{X}_{1}$, increasing in anticipation of the period 2 and 3 tax. However, while oil industry output in period 1 rises from 2.5 to 2.8 , coal production increases from 2.5 to $3.8 .{ }^{10}$ This result will be surprising to some. The transmission mechanism from future policy to current production is expected loss of future rents, and these rents are much lower for coal than for oil. However, this transmission mechanism influences decisions over larger stocks; the balance of forces is such that inter-temporal leakage and the green paradox is more of a problem in coal than in oil.

Table 3: Anticipated tax changes and inter-temporal leakage: oil and coal

\begin{tabular}{|l|cc|l|l|lll|}
\hline & $\mathrm{S}$ & $\mathrm{K}$ & Rent $(\tau=1)$ & Tax policy & $\mathrm{X}_{1}$ & $\mathrm{X}_{2}$ & $\mathrm{X}_{3}$ \\
Oil: no policy & 3 & 0.4 & 0.51 & $\mathrm{t}_{1}=0, \mathrm{t}_{2}=\mathrm{t}_{3}=0$. & 2.5 & 0.45 & 0.07 \\
Oil: future policy & 3 & 0.4 & 0.50 & $\mathrm{t}_{1}=0, \mathrm{t}_{2}=\mathrm{t}_{3}=0.1$ & 2.8 & 0.21 & 0.04 \\
Coal: no policy & 6 & 0.85 & 0.06 & $\mathrm{t}_{1}=0, \mathrm{t}_{2}=\mathrm{t}_{3}=0$. & 2.5 & 2.0 & 1.52 \\
Coal: future policy & 6 & 0.85 & 0.02 & $\mathrm{t}_{1}=0, \mathrm{t}_{2}=\mathrm{t}_{3}=0.1$ & 3.8 & 1.18 & 1.07 \\
\hline
\end{tabular}

Elasticity of demand $=10: 1$ period discount factor $=0.75$.

Once again, simple theory is only indicative, and parameter values for which this result holds remain to be investigated. However, it points to the need to have supplyside policies in place for the coal sector. The practical relevance of the 'green paradox' remains a matter of debate (see van der Ploeg 2013), but the arguments above suggest that it could be more of an issue in coal than in other sectors. If so, demand policies need to be complemented with supply policies that put in place a phased reduction in coal output.

\section{Closing Coal through Economic Incentives}

\footnotetext{
10 The higher emissions intensity of coal means that a carbon tax would be 30 percent higher in coal than in oil; $\mathrm{t}_{2}=\mathrm{t}_{3}=0.133$ in which case coal output increases from 2.5 to 4.1 . The text uses equal tax rates rate in order to focus on the effect of different stocks and extraction costs.
} 
The preceding section made the case for supply side policies in coal, given the potential leakage problems that arise as many decision takers are outside the coalition. We now consider the design of economic incentives to achieve this.

Focusing directly upon closing coal production instead of reducing the consumption of carbon-emitting energy brings several practical advantages. First, precisely because it aims to affect so many different activities, the carbon pricing approach is attempting to change the decisions of a diffuse and very large number of actors. The collective action problem increases in severity both as the number of actors increases (Becker, 1983), and as their diversity increases (Ashraf and Galor, 2013). In contrast, the production of coal is highly concentrated: it is largely conducted by only a few firms, employing a clearly identified group of workers, located in only a few countries. These are the only firms, workers and countries in which decisions would need to change in a major way. ${ }^{11}$ Of course, closing coal will also affect energy consumers, but this is an indirect and diffuse effect and so is unlikely to provoke collective action. The decisions of consumers will automatically adjust marginally as a result of the changes in energy prices consequent upon the closure of coal.

Second, because the changes in the decisions by coal producers are major, they are readily observable. Evidently, unless decisions are observable there is little prospect of compliance. The way that climate policy currently tries to achieve observability is through setting a target level for emissions, thereby turning a continuum into something discrete. However, this type of approach always suffers from the weakness that actors recognize that the target is arbitrary, so that the apparent necessity of abiding by it is illusory, as is evident from the limited success of targets for fiscal deficits. By focusing only on decisions which are major, our approach achieves observability without arbitrariness.

Third, other policies have outcomes that are highly uncertain. To date, caps and quotas have had wildly unpredictable effects on the price of carbon; investments in technological innovation have unpredictable pay-offs; and the promotion of bio-fuels has turned out to have unpredicted environmental consequences. This is debilitating for building consensus among those who must take the decisions because there is so much scope for disagreements about their consequences. As Haidt (2012) discusses, experimental psychology finds that decision takers are highly prone to select from among an array of evidence that which best suits their own interests. Hence, certainty of outcome considerably improves the chances of agreement. In contrast to the generic approaches that have been adopted to date, the direct consequences of the closure of coal can be known with a high degree of precision.

\footnotetext{
11 There are also administrative advantages of concentrating policy variables on a few agents, see Mooij et al (2012). Metcalf and Weisbach (2009) argue for levying a carbon tax 'upstream' (e.g. mines and ports rather than at the points of consumption) for administrative efficiency.
} 
Given an exogenous coalition of the willing, Harstad (2012) devised a straightforward economic mechanism for closing the global coal industry. The coalition should simply buy up and close coal fields (more generally, high cost fossil fuel deposits) worldwide. Harstad shows that the cost to the coalition of doing this (i.e. of compensating producers for output foregone) is less than the benefit received from moving closer to the coalition's objective, which includes a cost of damage from emissions. Full implementation of this produces an outcome which (assuming that members of the coalition care about climate damage and countries outside are completely indifferent to it) is first-best, in line with the Coase theorem.

This is a powerful result demonstrating how supply-side policy, including the purchase of deposits from outside the coalition, can potentially be in the interest of all parties and eliminate the leakage problem. However, it has various weaknesses. One is that the objective contains the coalition's evaluation of damage from emissions, but this is not necessarily that of the world. The 'first-best' result is therefore defined (and achieved) relative to a subset of countries, not the world as a whole; if this subset is very small, the outcome could be far away from a 'first-best' outcome for the entire world. ${ }^{12}$ Second, the size and membership of the coalition is taken as exogenous whereas, as we discuss in the next section, successful policy design should encourage coalition membership. ${ }^{13}$ A third weakness is that the approach implicitly assumes that property rights are absolute and uncontested. For example, a Saudi-Arabian oil company could buy and close an American coal mine without triggering any countervailing political process. In the next section we suggest why such a presumption is implausible.

Alternative market based approaches to managing supply can be imagined. The international community could establish a variant on the cap-and-trade system in which permits are required not for carbon emissions, but for the extraction of fossil fuel. For the reasons set out above, such a specialized arrangement should be easier than a generalized scheme. As with any cap-and-trade scheme, the allocation of the rents accruing to the initial assignment of the permits would need to be determined. Given the cap, such a system would produce an efficient phasing down of fossil fuels. The impact would fall largely on coal since the higher rents on oil would enable oilowners to out-compete coal owners for permits to extract. Of course, the system would depend upon fossil fuel producers adhering to it. This might be either because of exogenous enforcement by the global community, as in generalized cap-and-trade, which implicitly rests upon moral pressure. Alternatively, it could rely upon the incentives faced by a coalition (i.e. cartel) of fossil fuel producers. Monopoly power

\footnotetext{
12 The coalition might care about the entire world, but then consider what would happen if it were very small (just Norway). The cost of buying up world coal fields would be so (relatively) large that Norway's marginal utility of consumption relative to its marginal valuation of climate damage would increase, thereby reducing its willingness to buy fields.

${ }^{13}$ Harstad points out that the incentive to join the coalition depends on the division of the surplus between members and non-members.
} 
creates an incentive for this coalition to cut supply and raise price, but this does not mean that its actions (or objectives) are fully aligned with reducing carbon emissions. For example such a coalition might act to cut supply and raise price to a level just below that at which investment in renewables is profitable.

\section{Closing Coal through Moral Incentives}

All proposals for collective action on climate change are partially reliant upon moral pressure. While in economic analyses this is usually implicit, it is both feasible and helpful to make moral pressure explicitly endogenous. Adam Smith pioneered this analysis in The Theory of Moral Sentiments. We now know that moral values are 'hardwired' into human behaviour: natural selection has induced us, in some situations, to generate chemicals that stimulate moral choices (Pagel, 2011; Zak, 2012). We typically hold several coexistent moral values, one of which, fairness, is particularly pertinent for the collective action problem (Haidt, 2012). Behavioural economics is establishing that across a wide array of choices, once the choice is framed as a moral one, most people choose not to maximize their self-interest if doing so would be unfair. Fairness is not reducible to the Utilitarian calculus by which economists have traditionally tried to incorporate morality: Utilitarian ethical values predominate in only a small minority of the global population. So strategies devised on the basis of maximizing global utility may well be regarded as unfair. Not all the consequences of an action have moral force. Pinker (2007) demonstrates how moral attribution is embedded in language: 'the concept of causation we apply when choosing our verbs is also the concept we apply when we hold people responsible. We single out the acts that a person intentionally, and directly, and foreseeably caused.' (p. 228, our italics). An important implication is that general equilibrium consequences of actions have negligible moral force even if they loom large in the Utilitarian calculus.

Economic incentives interact with moral incentives. Indeed, it is possible for the former so to undermine the latter as to have perverse effects. In the recent literature the most celebrated example of economic incentives undermining moral incentives is the introduction of a fine for the late arrival of children at a nursery school in Israel (Levitt and Dubner, 2005). The fine backfired: the mechanism of internalisation inadvertently stripped the decision of its moral content and so eliminated the moral incentive to arrive on time. Analogously, the attempt to establish carbon markets creates a tension between economic incentives and moral pressure, which is why the sale of indulgences was so catastrophic for the sixteenth century Church.

\section{The Dynamics of Collective Action}

Many public goods problems are dynamic: people take their decision in sequence. The dynamics of the economic incentives for free-riding in a sequential game are straightforwardly perverse: the returns to free-riding increase the more that other people have already behaved 'decently' by acting in the collective interest. Just as the agent who free rides does not take into account the effect of his decision on the wellbeing of others, so he does not take into account its effect on the decisions of others. We will term this special sort of externality a decision externality. 
Although the specifics of our collective action problem of closing coal are important, it will be insightful to use a generic example of collective action, and for this we use the canonical set-up of cows overgrazing the commons. We will imagine that villagers have agreed that all their cows should be taken off the commons to let it recuperate, but that the timing of each person's journey to the commons to remove their cows has been is left to individuals and so will be sequential. The economic cost of compliance increases as the sequence of removal proceeds: this is the cumulative effect of the decision externalities noted above. The more cows that have already been removed by others the greater the benefit from leaving cows to continue grazing. But by viewing the collective action problem in dynamics it is apparent why the economic perspective is inadequate. As people remove their cows from the commons, while the economic cost of good behaviour increases, so does the moral pressure. The last person with a cow on the commons indeed has the strongest economic incentive to leave it there, but will be subject to the strongest moral pressure, both communal and internal, to remove it. That is, there are two opposing decision externalities, one economic, the other moral. The moral decision externality changes the moral incentive for the agent to leave his cows on the commons because it changes his and his community's judgment of whether the decision is unfair. However, while both effects cumulate, the change in the economic incentive can reasonably be seen as far smaller than the change in the moral incentive. This can be seen by comparing the beginning and the end of the sequence: non-compliance with full compliance. Although the economic incentive to leave cows on the commons is at its maximum in the neighbourhood of full compliance, it remains large even in the neighbourhood of zero compliance. In contrast, the change in the moral incentive for free-riding is huge. Whereas in the neighbourhood of zero compliance, not to free-ride would be quixotic, in the neighbourhood of full compliance to free-ride would be psychopathic. That the moral decision externalities cumulate so strongly has important implications.

In the neighbourhood of full compliance, collective action may not face a free-rider problem: the moral pressure to comply may be so strong that it overwhelms the economic incentive to free-ride. In contrast, in the neighbourhood of zero-compliance there has been no accumulation of moral decision externalities and so the moral incentive to act is virtually non-existent. Since no other actor has yet behaved ethically there is no moral pressure to do otherwise. To summarize, in a sequential collective action problem each decision generates two types of decision externalities, one on the economic incentive to free-ride and the other on the moral incentive. ${ }^{14}$ Because moral pressure is at its weakest in the initial stages of behavioural change, for collective behaviour to be ignited, it is necessary to provide a convincing argument as to why and how change should be sequenced.

\section{Can the moral decision externality be internalized?}

As moral decision externalities cumulate, the overall incentive to comply, consisting of the sum of the economic and moral incentives, is weaker in the early stages of the sequence than in the later stages. Presented with a new type of externality, conventional economic analysis has its standard solution of creating a market mechanism for internalization. Since the moral externalities are most valuable in the

\footnotetext{
${ }^{14}$ The process by which a moral action spreads across a population is analogous to wildfire protests analysed by Kuran (1989). As in that model, an essential feature for spreading is that there should be no wide gaps in attitudes: the more morally motivated should not be readily distinguished from other actors by some other observable feature. An evident weakness of the Kyoto approach was that it singled out developed countries as distinctively responsible.
} 
early stages of achieving collective action, a market mechanism could offer a financial reward to early compliers. We see something of this used in global warming policies, through financial incentives for the early adoption of green technology. However, as argued by Sandel (2011), resort to markets has ethical implications. Since the need for sequencing arises precisely because of the need to harness the power of moral values, it is important that the basis for selecting the sequence should not undermine the moral force of the sequence itself. Were those early in the sequence of collective compliance differentially rewarded it would undermine the moral force exerted later in the sequence. Moral decision externalities are only generated if early compliers generate in others a sense that continued non-compliance would be unfair. As a matter of logic, moral goodness cannot be bought.

\section{Principles for Determining Sequence}

To solve the collective action problem, agents must therefore collectively agree a sequence of compliance which has moral force with the actors who are going to be subject to the sequence. If it is not seen as morally legitimate by those early in the sequence it will not ignite collective action. If it is not seen as morally legitimate by those late in the sequence it will not harness the potential for the force of fairness to grow with compliance and so drive an ignited process through to completion. Viewed in isolation, there is only one basis for selecting a sequence that can satisfy the conditions for fairness, namely random assignment. This is the only mechanism which satisfies the Rawlsian veil of ignorance condition: ex ante, every actor has an equal chance of attaining a favourable (that is, late) position in the sequence of compliance. However, the fairness of a sequence cannot be derived separately from the underlying morality of the specific collective action with which it is concerned. Whether a proposed sequence is regarded as fair will be assessed in the context of the purpose to which it is being harnessed: namely compliance with some specific collective action. Returning to the canonical collective action problem, suppose that the villagers were to agree to a random assignment of the sequence in which they should withdraw their cows. The random sequence happens to assign the responsibility for the first cow to be removed from the commons to a poor widow, while letting the rich landowner leave his herd on the commons until everyone else has complied. The poor widow might feel under little personal moral pressure to comply, and other villagers might be hesitant to bring the force of moral censure to bear on her. The random assignment of sequence is fair in isolation, but the sequence it has produced is judged unfair because its purpose, to stop overgrazing, is linked to another distribution, the ownership of cows on the common. If the collective action problem is to be solved, the owner of the largest herd will have to move before the widow.

The moral basis for sequence must therefore be recognized as ethical in relation to the larger purpose of the collective action. As noted above, in assessing fairness actors are not impartial assessors of the evidence (Haidt, 2012). In respect of global warming, as with cows on the commons, a randomized sequence for carbon reductions would self-evidently not induce compliance. Most of the countries unlucky enough to draw an early place in the sequence would be able to find some moral alibi for non-compliance by contrasting themselves with some more culpable country that was not obliged to comply until later.

Applying the Analysis to the Global Coal Industry 
The essential feature, which focuses both on a particular industry and its closure, is $a$ highly targeted sequence of moral responsibility. At any one time, responsibility for progress on tackling global warming should rest clearly with the population of a particular country, and indeed specific actors within it, rather than be diffused across the global population, thereby dissipating its moral energy. Further, as discussed, the basis for sequence must be compatible with the existing moral narratives of global warming. Three distinct narratives have gained some acceptance. One is that action to tackle global warming will be costly and so should be borne disproportionately by those who have the ability to pay: thus the sequence of reduction should be according to income. A second is that the problem of global warming arises because people in some societies are emitting far more carbon than other societies: thus, the sequence of reduction should be according to current emissions. A third is that the problem arises because of the accumulated stock of past emissions: thus, the sequence of reduction should be according to cumulative emissions.

Note that in isolation none of these narratives has been sufficiently convincing to exert significant moral pressure. They have been deployed much more vigorously as alibis for inaction by those societies they exonerate, than as an impetus to action by those societies they implicate. But to date their potential moral force has been triply dissipated. First, the narratives have not been used to generate a finely grained sequence, but rather to attempt to revive the vanished dichotomous world of developed versus developing countries, a classification of manifest irrelevance to policies for global warming. No sequence which required 'developed countries' to act while 'developing countries' did not, was likely to be regarded as fair by the citizens of developed countries. The second reason why moral force has been dissipated is that the narratives have not been linked to specific actions, but only to aggregate targets. This breaches the requirement that for moral force a specific action attributable to a specific actor must be directly linked to a specific consequence. Actions must therefore be readily observable and manifestly material to global carbon emissions. The final reason why moral force has been dissipated is that none of these three narratives has sufficient legitimacy to dominate the others, but nor can any of them be dismissed. As a result, they have competed with each other, thereby enabling each actor to weight them according to whatever is most advantageous for them (the Haidt bias).

Closing down the global coal industry meets the key features that give an action moral force. It is a concrete event, readily observable, and directly under the control of identifiable actors. It is also manifestly material to the global problem of carbon emissions. Fortunately, there is little room for ambiguity as to an ethically reasonable sequence of closure. There are only a few countries whose coal industry is currently material: a truly global sequence is unnecessary, greatly simplifying the process of agreement. These countries are China, USA, India, Australia, Russia, Germany, Poland, Indonesia and South Africa. They differ massively on all three criteria, but the rankings are largely coincident. Any reasonable weighting of the three criteria income, current emissions, and past cumulative emissions - will produce a very similar sequence among this group. Evidently, the USA, Australia, and Germany are sufficiently similar that, given the leeway to interpret criteria to one's own advantage, none of them would be willing to accept that they should close their coal industry ahead of the others. They will therefore need to move together. However, the three are collectively sufficiently different from all the other countries any each of the three criteria, that they can readily be identified as the first movers. The next group is probably Russia and Poland, both upper-middle-income countries with a long history 
of high carbon emissions. After them come China and South Africa, followed by Indonesia and India.

A deal to close coal thus requires gaining prior agreement from these salient coal producers that the above sequence will be the order in which their coal industries are closed down. Because the agreement can be confined to this small group, the closure of the world's coal industry may be a more viable strategy than the attempts to negotiate a generalized global deal. In practice, negotiations between so many actors have proved to be very vulnerable to hold-outs. The agreement would also cover the timescale for closure, and rules concerning the permitted production of countries later in the sequence. For example, it might be reasonable that the countries next in the sequence for closure should not increase their production. Hence, the USA, Australia and Germany would agree to a timetable for closure of their own coal industries only if, during this period, Russia and Poland agreed not to increase their production. China and South Africa would be permitted to increase their production only until the first group had completed their closure programs, at which point, once Russia and Poland began their own closure programs they would become bound by the rule of non-expansion. Collectively, the group of salient coal producers would have an interest in preventing free-riding from other producers and potential entrants to the industry. A possible rule would be for them to extrapolate the bands from their own group to global coverage: thus, the USA-Australia-Germany rule would apply to all other countries judged to be sufficiently similar. While ex ante the agreement of all these countries might not be sought, non-compliance by any of them might be deemed to freeze the entire agreement.

\section{The interactions of moral pressure and economic incentives}

We now consider how moral pressure might interact with various designs of economic incentives. First, we return to the Harstad proposal for a coalition of the willing to buy the rights to coalmines and close them down.

\section{Moral pressure and the Harstad proposal}

Although Harstad postulates an exogenous international coalition of the willing, no such coalition would in fact be necessary in order to implement his proposal. Any country with a coal industry that valued a reduction in carbon emissions sufficiently highly to be eligible for the coalition could implement the policy unilaterally. That the USA and Australia are exporting coal suggests that even very wealthy countries are not sufficiently motivated to implement it. The international dimension introduced by a coalition makes such a policy considerably less plausible because it introduces a countervailing moral narrative of considerable force. For example, the attempt by the Australian company BHP-Billiton to purchase the Canadian potash company Potash Corp, was blocked by the Canadian government due to intense opposition from the residents of Saskatchewan based on fears of closure. Even had the motivation for the bid been to reduce carbon emissions it is highly unlikely that this would have affected the outcome: the obvious Canadian retort would have been 'why us?' A likely first choice for a coalition of the willing would be to close coalmines in South Africa, due to its combination of highly polluting coal and relatively expensive labour. But if Australian money cannot close a mine in Canada, it is not difficult to assess the prospects of American money been able to close a coalmine in South Africa. Economists schooled in Utilitarianism are inclined to interpret such impediments as revealing merely a lack of political will to confront self-interest. However, it is important to recognize that this framework is merely one of many, and indeed one that 
is relatively uncommon. The people on the streets of Johannesburg would be as impassioned with moral righteousness as any economist and in a democracy their moral perspective would rightly determine policy.

We conclude that the Harstad proposal is severely undermined through its interaction with moral pressure.

\section{Moral pressure and generalized compensation for sequential closure}

Would our proposed scheme for sequential closure by targeted moral pressure be reinforced by the addition of compensation for the loss of coal rents paid by other countries?

A reasonable moral case can be made for compensation. Collectively the salient coal producing countries would be sacrificing their rents on coal to provide a public good that would benefit other countries. However, there is also a reasonable moral case against compensation. Rents are by definition unearned income. Rents on natural assets are unevenly distributed around nations: countries without coal have not been fortunate enough to own any coal rents. Further, since the closure of the global coal industry would inflict losses of rents on coal consumers, should they also be compensated? But consumers of coal, actual and prospective, are a vast and amorphous group. The case against compensation is sufficiently tenable that those whose self-interest is to weight it highly would presumably do so. The USA, Australia and Germany would not receive compensation from the rest of the world for closing coal.

\section{Tradable extraction permits: sequential closure with oil-for-coal compensation}

Finally, we consider a variant of our morally based sequence of coal closure in which compensation for closure is financed by allocation of permits in the ring-fenced capand-trade scheme for the extraction of fossil fuels described at the end of Section 4. As in a scheme without compensation, in the first phase the three high-income coal producers would gradually close their coalmines. But now, additionally, a limit would be set to the extraction of all fossil fuels in high-income countries. The rights to extract would be distributed among the high-income fossil fuel producers pro-rata to their current production. Through this ring-fenced cap-and-trade market, oil producers in the high-income countries would buy permits from coal producers. In effect, the state oil companies of Norway and Saudi Arabia would compensate German coalminers for the closure of their industry. Once Germany, the USA and Australia had closed their coalmines, the next income tier of coalmines and oil wells would be brought into the cap-and-trade scheme, joining the high-income oil producers. The scheme could potentially be supplemented by an enforcement mechanism: producers who did not abide by the scheme would not be permitted to sell their output in highincome countries.

How might the addition of this cap-and-trade scheme affect the moral pressure for sequential closure? Oil extraction is dominated by unearned rents whereas coal extraction is dominated by hard-earned labour income. Thus, compensation of coalminers by oil companies could invoke a supportive moral narrative of fairness. The Haidt bias might now work in favour of action: coalminers in high-income countries who accepted closure could tell themselves both that they were in the vanguard of action to address climate change, and the just recipients of the oil wealth that fortune had assigned to others. The economic and moral incentives would thus be mutually reinforcing. 


\section{A final reality check}

Any effective scheme for containing global warming will at some stage require coalmines in middle-income countries to close. In thinking of the obstacles that need to be overcome it is helpful to become concrete and so we consider the closure of Polish coalmines. We compare the prospects for closing Poland's mines by three different strategies: generalized carbon taxes; the Harstad proposal; and our targeted sequence of closure supplemented by ring-fenced cap-and-trade in fossil fuels. The carbon tax approach would close Polish coal through reducing demand to the point at which the industry was bankrupted. However, since Poland could burn its own coal, this would depend upon the Polish Government implementing the tax. In turn, this would only happen if Polish citizens thought in combination the moral and economic incentives were decisive: compliance was morally right, and noncompliance would lead to trade sanctions. Thus posed, it is apparent that the economic incentive of sanctions would be liable to undermine the moral incentive of solidarity with global efforts to arrest climate change. The moral narrative of national solidarity would most likely overwhelm that of global solidarity. As an analogy, President Mugabe has just won an election in which reactance to foreign pressure trumped moral arguments more powerful than any in the armoury of climate change. If global carbon taxation looks unlikely to close Polish coal, the Harstad proposal appears yet more doomed. A coalition-of-the-willing trying to buy Polish coalmines to close them down would be highly likely to be frustrated by Polish nationalism. Our proposed approach might also fail, but it would harness two powerful pressures. Morally, Polish coalminers would hold the fate of the planet in their hands; the coalminers of Germany, America and Australia would already have accepted closure. The economic incentive would be that Polish miners could, by selling extraction permits, gain entitlement to a share of foreign oil wealth. The incentive might be strengthened were the opportunity to trade time-bound: resistance would risk leaving a doomed industry without a lifeline.

\section{Concluding comments}

Discussion of public policy on global warming has been dominated by two barelyrelated approaches. Economists have proposed generalized solutions based on economic incentives for reduced emissions in consumption and production through carbon taxes and cap-and-trade. Meanwhile environmental activists have attempted to galvanize moral energy, usually through attributing responsibility to affluent consumers for highly specific actions such as car purchases. We have attempted to integrate the two approaches by focusing on a single salient decision: coalmining. We have shown that even from the perspective of economic incentives, due to leakage there are strong reasons for switching emphasis from the generalized demand for carbon emissions to the supply of coal. These are reinforced when trying to harness moral pressure. By switching from generalized global emissions targets to a highly specific sequence of closure decisions for coal, the intensity of moral pressure can be increased. While economic incentives have to date inadvertently undermined moral pressure, we propose how they could be reinforcing: a ring-fenced fossil fuel cap-andtrade scheme could provide compensation from oil rents for the costs of closing coalmines. Details of such schemes need to developed more fully and are, we think, an urgent direction for research. 


\section{References:}

Ashraf, Q. and O. Galor (2013) 'The Out-of-Africa Hypothesis: Human Genetic Diversity and Comparative Economic Development', American Economic Review, 103(1):1-46.

Becker G.S. (1983) 'A Theory of Competition among Pressure Groups for Political Influence', Quarterly Journal of Economics, 98: 371-400.

Bowen, B. and M. Irwin (2007) 'Coal Transportation Economics', https://www.purdue.edu/discoverypark/energy/assets/pdfs/cctr/outreach/Basics 7-Transportation-Apr07.pdf

BP Statistical Review (2013), BP, London.

Chen, Y. A. Ebenstein, M. Greenstone and H. Li (2013) 'Evidence on the impact of sustained exposure to air pollution on life expectancy from China's Huai River policy', Proceedings of the National Academy of Sciences, doi:10.1073/pnas.1300018110

Clements, B. D. Coady, S. Fabrizio, S. Gupta, T. Alleyen and C. Sdralevich, (2013) Energy subsidy reform, IMF Washington DC

European Environment Agency (2008) 'Air pollution from electricity-generating large combustion plants', Copenhagen:, ISBN 978-92-9167-355-1. Link from http://en.wikipedia.org/wiki/Fossil-fuel_power_station.

Grantham Institute (2013) 'Unburnable carbon 2013; wasted capital and stranded assets', LSE, London

Health and Environment Alliance (2013) The unpaid health bill: how coal power plants make us sick www.env-health.org/unpaidhealthbill

Haidt, J. (2012) The Righteous Mind: why good people are divided by politics and religion, Allen Lane.

Harstad, B. (2012) 'Buy coal: a case for supply side environmental policy; Journal of Political Economy, 120: 77-115.

Hoel, M. (1994). "Efficient Climate Policy in the Presence of Free Riders."Journal of Environmental Economics and Management 27, 259-74.

Hoel, M. (1996). "Should a Carbon Tax Be Differentiated across Sectors?" Journal of Public Economics 59, 17-32.

International Energy Agency (2011) World Energy Outlook, Paris.

Jakob, M., R. Marschinski and M. Hubler, (2013)'Between a rock and a hard place; a trade-theory analysis of leakage under production and consumption based policies', Environmental and Resource Economics, 56, 47-72.

Kuran, T. (1989) 'Sparks and Prairie Fires: a Theory of Unanticipated Political Revolution', Public Choice, 61, 61-74.

Lemoine, D. (2013) 'Green expectations; current effects of anticipated carbon pricing', University of Arizona working paper 13-09.

Levitt, S.D. and S.J. Dubner (2005) Freakonomics, William Morrow, New York

Metcalf, G.E and D. Weisbach (2009) 'The design of a carbon tax' Harvard Environmental Law Review, 33, 499-556.

Mooij, R., M. Keen and I. Parry (2012) 'Fiscal policy to mitigate climate change; a guide for policy makers', IMF Washington DC.

Pagel, M. (2011) Wired for Culture: the Natural History of Human Cooperation, Allen Lane.

Pinker, S. (2007) The Stuff of Thought: Language as a Window into Human Nature, Allen Lane.

Ploeg, van der F. (2013) 'Cumulative carbon emissions and the green paradox' Annual Review of Resource Economics, 5, 281-300. 
Sinn, H.-W. (2008) 'Public policies against global warming: a supply side approach',International Tax and Public Finance, 15: 360-394.

Sinn, H.-W. (2012) The Green Paradox: A Supply-Side Approach to Global Warming, Cambridge, Mass: MIT Press.

Zak, P. (2012) The Moral Molecule, Dutton. 


\section{Appendix}

\section{International leakage:}

The two equations below give the equality of supply and demand for fuels $\mathrm{C}$ and $\mathrm{G}$ respectively. There are $\mathrm{N}$ countries in the world, of which $\mathrm{M}$ are in the coalition. The right hand side of each equation is supply, with producer prices $p_{C}$ and $p_{G}$ and elasticity $\eta . S_{C}$ is a supply shifter for C, taking value less than unity if supply is cut. On the left hand side, the elasticity of demand for fuel is $\epsilon$, and fuel is a CES aggregate of $\mathrm{C}$ and $\mathrm{G}$ with elasticity of substitution $\sigma$ and weights $1-\gamma, \gamma$. The coalition may uses taxes $t_{C}, t_{G}$, which set the consumer price above the producer price, or reduce demand for $\mathrm{C}$ directly by shifting $D_{C}$ below unity.

$$
\begin{aligned}
& M D_{C}\left(p_{C}+t_{C}\right)^{-\sigma}\left[(1-\gamma)\left(p_{C}+t_{C}\right)^{1-\sigma}+\gamma\left(p_{G}+t_{G}\right)^{1-\sigma}\right]^{(\varepsilon-\sigma) /(\sigma-1)} \\
+ & {[N-M] p_{C}^{-\sigma}\left[(1-\gamma) p_{C}^{1-\sigma}+\gamma p_{G}^{1-\sigma}\right]^{(\varepsilon-\sigma) /(\sigma-1)}=M S_{C} p_{C}^{\eta}+[N-M] p_{C}^{\eta}, } \\
& M\left(p_{G}+t_{G}\right)^{-\sigma}\left[(1-\gamma)\left(p_{C}+t_{C}\right)^{1-\sigma}+\gamma\left(p_{G}+t_{G}\right)^{1-\sigma}\right]^{(\varepsilon-\sigma) /(\sigma-1)} \\
+ & {[N-M] p_{G}^{-\sigma}\left[(1-\gamma) p_{C}^{1-\sigma}+\not p_{G}^{1-\sigma}\right]^{(\varepsilon-\sigma) /(\sigma-1)}=M p_{G}^{\eta}+[N-M] p_{G}^{\eta} . }
\end{aligned}
$$

Equilibrium prices are the solution of this pair of equations, and table 3 reports comparative statics. It uses parameters $\varepsilon=1, \sigma=5, \eta=1, N=1, M=0.5, \gamma=0.5$. Initial equilibrium prices (with $S_{C}=D_{C}=1$ and $t_{C}, t_{G}=0$ ) are all equal to unity.

\section{Intertemporal leakage:}

The profits of a representative price taking firm are $\pi \equiv\left(p_{\tau}-K\right) X_{\tau} \beta^{\tau}$ where $p_{\tau}$ is the price in period $\tau, K$ the extraction cost, $X_{\tau}$ the quantity produced and $\beta$ the one period discount factor. The firm operates for periods $\tau \in[0, T]$, and has total resource stock $S$, so maximises $\pi$ subject to $\sum_{\tau=1}^{T} X_{\tau} \leq S$. If production takes place in all periods and the resource stock constraint binds, then first order conditions are $\left(p_{\tau}-K\right)=\left(p_{T}-K\right) \beta^{T-\tau}$ for all $\tau$. The demand curve is $X_{\tau}=\left(p_{\tau}+t_{\tau}\right)^{-\varepsilon}$ where $t_{\tau}$ is the period $\tau$ tax rate. This, with first order conditions and the resource constraint, gives the usual Hotelling price path and associated path of quantities. The example of table 3 has $T=2, \beta=0.75$, and $\varepsilon=10$. 